\title{
Utilização da casca de ovo como fonte de correção da acidez do solo
}

Na literatura são registrados poucos trabalhos relacionados à utilização de resíduos orgânicos como corretivos da acidez do solo. A casca de ovo é composta principalmente por carbonato de cálcio, sendo esta fonte de um importante nutriente responsável por auxiliar o metabolismo vegetal. $\mathrm{O}$ objetivo foi avaliar a eficiência do uso da casca de ovo na correção da acidez do solo comparado ao calcário dolomítico. O experimento foi conduzido em casa de vegetação, do instituto de ciências agrarias, área de ciência do solo da Universidade Federal Rural da Amazônia - UFRA, campus Belém/PA. Foi utilizado o delineamento experimental inteiramente casualizado com nove tratamentos distribuídos em quatro repetições. Os tratamentos foram alocados em vasos com capacidade de $3 \mathrm{dm} 3$ em que as quantidades de 2,25; 4,5; 5,25; e $6 \mathrm{~g}$ de casca de ovo e calcário dolomítico foram aplicadas de acordo com análise química do solo. 0 experimento teve a duração de 90 dias, em que foram avaliados o pH em 30, 45, 60 e 75 dias durante a condução. Obteve-se efeitos positivos dos corretivos aplicados nas diferentes dosagen usadas, em relação ao $\mathrm{pH}$, nos períodos de avaliação dos tratamentos. Devido à facilidade de aquisição da casca do ovo, esta pode ser considerada uma boa alternativa para pequenos produtores devido ser considerada um produto residual.

Palavras-chave: Resíduos Sólidos Orgânicos; Calcário Dolomítico; Cálcio.

\section{Use of egg shell as source of correction of soil acidity}

There are few studies in the literature related to the use of organic residues as soil acidity correctors. Eggshell is mainly composed of calcium carbonate, which is an important nutrient responsible for helping plant metabolism. The objective was to evaluate the efficiency of the use of eggshell in correcting soil acidity compared to dolomitic limestone. The experiment was conducted in a greenhouse, at the agrarian science institute, in the soil science area of the Federal Rura University of the Amazon - UFRA, campus Belem/PA. A completely randomized design was used with nine treatments distributed in four replications. The treatments were allocated in pots with a capacity of $3 \mathrm{dm} 3$ in which the amounts were $2.25 ; 4.5 ; 5.25 ;$ and $6 \mathrm{~g}$ of eggshell and dolomitic lime were applied according to chemical analysis of the soil. The experiment lasted 90 days, in which the $\mathrm{pH}$ was evaluated at 30, 45, 60 and 75 days while driving. Positive effects of the correctives applied were obtained in the different dosages used, in relation to the $\mathrm{pH}$, in the evaluation periods of the treatments. Due to the ease of acquisition of the eggshell, this can be considered a good alternative for small producers because it is considered a residual product.

Keywords: Organic Solid Waste; Dolomitic Limestone; Calcium.

Topic: Desenvolvimento, Sustentabilidade e Meio Ambiente

Reviewed anonymously in the process of blind peer
Received: $14 / 03 / 2020$

Approved: 08/04/2020
Jessivaldo Rodrigues Galvão (iD

Universidade Federal Rural da Amazônia, Brasil http://lattes.cnpq.br/0013591065769741 http://orcid.org/0000-0003-4242-6555 jessigalva050@gmail.com

Sandro Rogério Almeida Casanova (iD Universidade Federal Rural da Amazônia, Brasil http://lattes.cnpq.br/0645347247561206 http://orcid.org/0000-0002-8625-0582 rogerio.casanova89@gmail.com

Francisco José Lima de Souza (iD) Universidade Federal Rural da Amazônia, Brasil http://lattes.cnpq.br/8134872514883156

http://orcid.org/0000-0002-1289-414X franciscosouzacr33@gmail.com

\section{Mateus Augusto de Carvalho Santana (D) Universidade Federal Rural da Amazônia, Brasil http://lattes.cnpq.br/4613681446308132 http://orcid.org/0000-0002-4982-7311 ma1041578@gmail.com \\ Mauro Junior Borges Pacheco (iD \\ Universidade Federal Rural da Amazônia, Brasil http://lattes.cnpq.br/0756046215703468 http://orcid.org/0000-0001-6024-7054 mauro.jr720@gmail.com}

Luiz Felipe Conceição Tavares de Assis (iD Universidade Federal Rural da Amazônia, Brasil http://lattes.cnpq.br/2451308405569394 http://orcid.org/0000-0001-5811-915X luizassis1509@gmail.com
Bruno Kleidson da Silva Maia (iD)

Universidade Federal Rural da Amazônia, Brasil http://lattes.cnpq.br/7499950655282322 http://orcid.org/0000-0002-8494-6834 brunokleidson@gmail.com

Dênmora Gomes de Araujo

Universidade Federal Rural da Amazônia, Brasil http://lattes.cnpq.br/0359372594622313 http://orcid.org/0000-0001-9907-1105 denmora.araujo@ufra.edu.br

\section{Referencing this:}

GALVÃO, J. R.; CASANOVA, S. R. A.; SOUZA, F. J. L.; SANTANA, M. A. C.; PACHECO, M. J. B.; ASSIS, L. F. C. T.; MAIA, B. K. S.; ARAÚJO, D. G. Utilização da casca de ovo como fonte de correção da acidez do solo. Nature and Conservation, v.13, n.2, p.77-81, 2020. DOI: http://doi.org/10.6008/CBPC2318-2881.2020.002.0008 


\section{INTRODUÇÃO}

Os resíduos sólidos são classificados, segundo a lei de política nacional de resíduos sólidos 12305/10, em: domiciliares, de limpeza urbana, de estabelecimentos comerciais e prestadores de serviço, industriais, de serviços da saúde, da construção civil e de mineração. Podem ser distintos, ainda, em úmidos e secos, orgânicos e inorgânicos e perigosos e não perigosos. Dentro destas definições, entende-se que resíduos sólidos orgânicos é todo resíduo de origem animal ou vegetal, ou seja, que recentemente fez parte de um ser vivo, como por exemplo: frutas, hortaliças, restos de pescados, folhas, sementes, cascas de ovos, restos de carnes (BENTO et al., 2013).

A casca do ovo contém, em média, 5,6 g de matéria inorgânica, sendo a maior parte composta de carbonato de cálcio (96\%), carbonato de magnésio (1\%) e fosfato de cálcio (1\%). A parte orgânica, pouco expressiva, é representada por proteínas. Por ser rica em cálcio, a mesma, disponibiliza um elemento fundamental e indispensável para o metabolismo vegetal. O cálcio participa na formação da parede celular dos vegetais, dessa forma está intimamente ligado ao desenvolvimento estrutural das plantas (formação de folhas, caule e raízes). Consequentemente, a deficiência desse elemento pode ser detectada quando as folhas mais novas de uma planta apresentar clorose (amarelecimento das folhas) internerval seguida de necrose (secagem das folhas) e crescimento desuniforme, além de morte das gemas terminais.

A acidez do solo pode ser gerada por diversos fatores tanto de caráter natural quanto antrópico. 0 desenvolvimento do solo sob um material de origem pobre em cátions básicos, assim como condições pedogenéticas que favoreçam a remoção de bases, contribuindo para o acúmulo de cátions ácidos como $\mathrm{Al}^{3}+$ e $\mathrm{H+}$, podem resultar na formação de um solo ácido. Da mesma maneira, o cultivo de plantas, a adoção de sistemas de cultivo que utilizam o revolvimento do solo, bem como o uso de fertilizantes de reação ácida, constituem práticas de manejo que contribuem para a acidificação do solo (ERNANI et al., 2001).

A calagem é a prática mais eficiente para a correção da acidez dos solos, já que promove a elevação do $\mathrm{pH}$, da saturação por bases e dos teores de cálcio, além de reduzir os níveis de alumínio e manganês trocáveis no solo (CAIRES et al., 2004). Mediante aos poucos trabalhos relacionados à utilização de resíduos de casca de ovo, para atenuar a acidez do solo, o objetivo foi avaliar a eficiência da casca de ovo como alternativa no auxílio a correção da acidez comparados a aplicação do calcário dolomítico.

\section{MATERIAIS E MÉTODOS}

O experimento foi conduzido foi desenvolvido em casa de vegetação, no instituto de ciências agrarias, área de ciência do solo da Universidade Federal Rural da Amazônia - UFRA, em Belém/PA. De acordo com classificação de Köppen, o clima predominante na região é o Afi com temperatura média anual de $26^{\circ} \mathrm{C}$, com alta pluviosidade, sendo a média de $2.754,4 \mathrm{~mm}$ anuais. As amostras do solo foram coletadas nas profundidades de 0,0 a 0,2m. O solo utilizado foi o Latossolo Amarelo distrófico, classificado de acordo com o Sistema Brasileiro de Classificação do Solo (EMBRAPA, 2006), e realizadas as análises químicas de acordo com metodologia conforme Embrapa (1997). Os resultados das análises químicas estão descritos na Tabela 
1.

Tabela 1: Caracterização química do solo, nas camadas de $0-0,2 \mathrm{~m}$ de profundidade, antes da instalação do experimento.

\begin{tabular}{|c|c|c|c|c|c|c|c|c|c|}
\hline \multirow{2}{*}{ Amostra } & \multirow{2}{*}{$\mathbf{p H}\left(\mathrm{H}_{2} \mathrm{O}\right)$} & \multirow{2}{*}{ pH (KCl) } & $\mathrm{Ca}^{2+}$ & $\mathrm{Mg}^{2+}$ & $\mathbf{H}+\mathbf{A l}$ & \multirow{2}{*}{$\frac{\mathrm{C}}{\mathrm{g} \mathrm{dm}^{-3}}$} & $\mathbf{P}$ & $\mathbf{N}$ & $\mathbf{K}$ \\
\hline & & & ........ & nolc dn & ......... & & \multicolumn{3}{|c|}{$\ldots . \ldots \ldots . . . \mathrm{mg} \mathrm{dm}^{-3}$} \\
\hline $0-20 \mathrm{~cm}$ & 4,49 & 4 & 0,19 & 0,66 & 9,63 & 18,5 & 3,6 & 18,5 & 0,034 \\
\hline
\end{tabular}

O experimento foi dividido em nove tratamentos em um delineamento experimental inteiramente casualizado distribuídos em quatro repetições. As composições dos tratamentos são apresentadas na Tabela 2.

Tabela 2: Tratamentos avaliados.

\begin{tabular}{c|c}
\hline Tratamentos & Descrição \\
\hline T1 & Solo Natural \\
T2 & Solo $+1500 \mathrm{~kg} \mathrm{ha}^{-1} \mathrm{C} . \mathrm{O}$ \\
T3 & Solo $+3000 \mathrm{~kg} \mathrm{ha}^{-1} \mathrm{C} . \mathrm{O}$ \\
T4 & Solo $+3500 \mathrm{~kg} \mathrm{ha}^{-1} \mathrm{C} . \mathrm{O}$ \\
T5 & Solo $+4000 \mathrm{~kg} \mathrm{ha}^{-1} \mathrm{C} . \mathrm{O}$ \\
T6 & Solo $+1500 \mathrm{~kg} \mathrm{ha}^{-1} \mathrm{C} . \mathrm{D}$ \\
T7 & Solo $+3000 \mathrm{~kg} \mathrm{ha}^{-1} \mathrm{C} . \mathrm{D}$ \\
T8 & Solo $+3500 \mathrm{~kg} \mathrm{ha}^{-1} \mathrm{C} . \mathrm{D}$ \\
T9 & Solo $+4000 \mathrm{~kg} \mathrm{ha}^{-1} \mathrm{C} . \mathrm{D}$ \\
\hline
\end{tabular}

Para a implantação do experimento, foram adotadas quantidades de calcário dolomítico, tomando por base, o mesmo procedimento para a casca de ovo, ou seja, 1500, 3000, 3500 e 4000 (kg ha-1), calculadas de acordo com as propriedades químicas do solo.

Os tratamentos foram alocados em vasos com capacidade de $3 \mathrm{dm}^{3}$ em que as quantidades de 2,25; 4,5; 5,25; e 6 g foram aplicadas, em cada vaso, de acordo com as quantidades de calcário determinadas. 0 solo foi seco ao ar, destorroado e passado em peneira com malha de $5 \mathrm{~mm}$, em seguida, colocado em sacos plásticos com capacidade de $5 \mathrm{dm}^{3}$ e posteriormente nos vasos plásticos com de $3 \mathrm{dm}^{3}$. O calcário dolomítico e a casca de ovo foram incorporados ao solo de cada vaso, em seus respectivos tratamentos, permanecendo incubado por um período de 30 dias, ficando hermeticamente fechados, sendo movimentados duas vezes durante a semana.

A aquisição da casca de ovo branco foi realizada em estabelecimentos comerciais, que utilizam ovo como seu subproduto onde podemos citar: pães, doces, salgados entre ouros. O material adquirido foi lavado com detergente neutro por cerca de 30 minutos, seguido de água corrente. Após a secagem, feita ao ar, foi retirado o excesso da película que envolve a parte interna da casca com o intuito de aproveitar apenas a parte biocerâmica da mesma. O material foi triturado e macerado até a forma de pó. As análises químicas do material resultante (casca de ovo) constataram teores de 0,331 mg dm-3 de P e 17,83 mg dm-3 de K. Para Ca e $\mathrm{Mg}$, os valores foram de 4 e 0,5 cmolc dm-3 respectivamente. Para determinação dos teores de $\mathrm{N}, \mathrm{P}$ e $\mathrm{K}$ adotou-se a metodologia de Tedesco, 1995. Para o Ca e Mg a metodologia da Embrapa (1997).

O experimento foi conduzido por um período de 90 dias, em que foram avaliados o pH aos 30,45, 60 e 75 dias durante a condução. A determinação do $\mathrm{pH}$ foi realizada utilizando um eletrodo de vidro, em 
suspensão na proporção solo-líquido 1: 2,5. Foram 19 avaliadas ainda o número de folhas, alturas de planta e o peso da matéria verde da parte aérea ao final do experimento. Os resultados do experimento foram submetidos à análise de variância, comparadas pelo teste de Tukey, quando pertinente, e estudos de regressão. Para a obtenção dos resultados utilizou-se o programa estatístico SISVAR.

\section{RESULTADOS E DISCUSSÃO}

Na aplicação da primeira dosagem, ou seja, 1500 kg ha-1, os corretivos aplicados proporcionaram ao $\mathrm{pH}$ do solo, um comportamento semelhante. $\mathrm{O}$ pH máximo atingido foi de 5,09 e 5,19, respectivamente para casca de ovo e calcário dolomítico atingidos entre o segundo e o terceiro período de avaliação (Figura 1A). É possível observar o efeito da correção do solo com os materiais estudados já no segundo período de aplicação, apresentando resultados satisfatórios quanto a elevação do pH que, inicialmente correspondia a 4,49 (sem correção) atingindo 4,83 (casca de ovo) e 4,99 (calcário dolomítico). Porém, os materiais estudados como corretivos, não atingiram a faixa considerada ideal para a maioria das culturas agrícolas $(5,5$ a 6,5$)$.

Os efeitos da aplicação dos corretivos, correspondentes a segunda dosagem (3000 kg ha-1) se assemelharam (Figura 5B). Os valores de pH considerados máximos para os respectivos corretivos foram obtidos entre o segundo e terceiro período de aplicação, correspondente a 5,37 e 5,71, respectivamente para casca de ovo e calcário dolomítico. No entanto, apenas o calcário dolomítico alcançou elevação de pH dentro da faixa ideal de desenvolvimento para maioria das culturas $(5,5$ a 6,5$)$.

Como ocorreu com as quantidades anteriores, na terceira dosagem (3500 kg ha-1) os efeitos dos corretivos se assemelharam apenas para o calcário dolomítico, proporcionando $\mathrm{pH}$ de 5,87 entre o segundo e terceiro período (Figura $5 \mathrm{C}$ ). Já para a casca de ovo o valor máximo de $\mathrm{pH}$ atingido foi de 5,88 entre o terceiro e quarto período de avaliação. Estes valores já poderiam ser considerados ótimos para a maioria das culturas. Idêntico as duas primeiras quantidades de corretivos aplicadas, o mesmo desempenho foi observado na quarta dosagem (Figura 1D), em que o pH com a casca de ovo foi de 5,67 e 5,84 com calcário dolomítico, no mesmo período. Observa-se pequena redução nos valores de $\mathrm{pH}$ a partir da quarta dosagem indicando que já seriam necessários a correção do solo nas dosagens anteriores.

Os valores de $\mathrm{pH}$ encontrados nos corretivos aplicados são bem semelhantes, indicando pequena diferença, o que pode ser atribuído a granulometria e a concentração de Ca e $\mathrm{Mg}$ presentes nos materiais utilizados como corretivos da acidez do solo. Assim, Gonçalves et al. (2011) estudando a granulometria e doses de calcário em diferentes sistemas de manejo, constatou valores de $\mathrm{pH}$ mais elevados nos tratamentos utilizando calcário com granulometria mais fina. Este mesmo autor cita em seu trabalho que a velocidade de reação do corretivo e seu efeito residual são grandezas inversas, que se contrapõem, e os materiais finamente divididos reagem mais rapidamente no solo, e o efeito é mantido por um período mais curto do que os materiais que contêm quantidade de partículas mais grossas. 


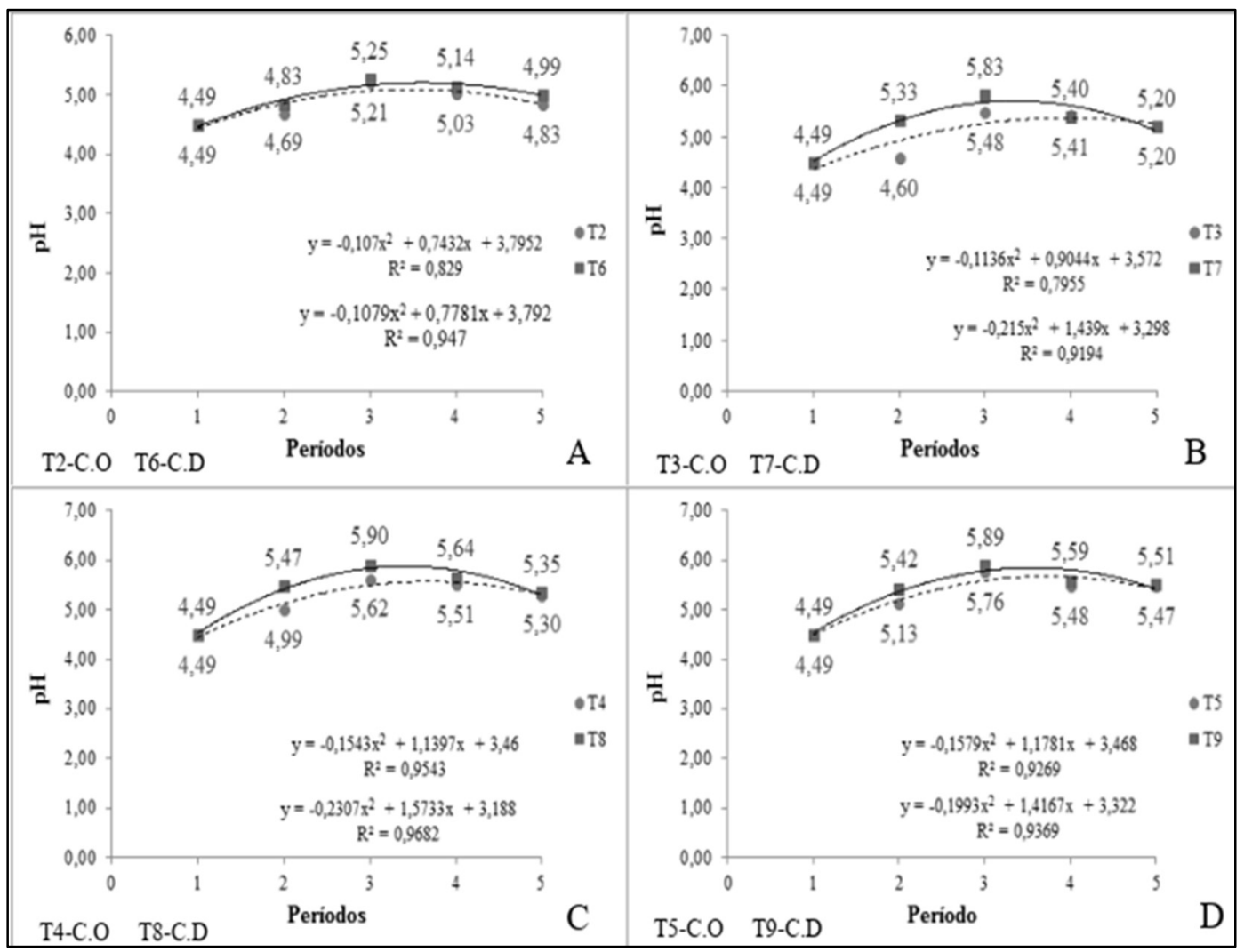

Figura 1: Comportamento do pH ao longo do período de avaliação do experimento.

\section{CONCLUSÕES}

Os efeitos da aplicação da casca do ovo como corretivo da acidez do solo podem ser considerados bastante efetivos em um curto espaço de tempo. A correção da acidez do solo realizada com a casca do ovo obteve efeitos similares ao calcário dolomítico. Devido à facilidade de aquisição, a casca do ovo pode ser considerada uma boa alternativa para pequenos produtores devido ser considerada um produto residual. A dose ideal dos corretivos para promover o valor máximo de pH é de 3500 kg há-1.

\section{REFERÊNCIAS}

BENTO, L. A.; TORRES, F. L.; LEMES, R. R.; MAGALHÃES, T. A.. Sistema de Gestão Ambiental para Resíduos Sólidos Orgânicos. Maceió: UNIFAL, 2013.

CAIRES, E. F.; KUSMAN, M. T.; BARTH, G.; GARBUIO, F. J.; PADILHA, J. M.. Alterações químicas do solo e resposta do milho à calagem e aplicação de gesso. Rev. Bras. Ci. Solo, v.28, p.125-136, 2004.

EMBRAPA. Centro Nacional de Pesquisa de Solos. Manual de métodos de análise de solo. 2 ed. Rio de Janeiro: EMBRAPA, 1997.

EMBRAPA. Centro Nacional de Pesquisa de Solos. Sistema brasileiro de classificação de solos. 2 ed. Rio de Janeiro, 2006.

ERNANI, P. R.; RIBEIRO, M. S.; BAYER, C.. Modificações químicas em solos ácidos ocasionadas pelo método de aplicação de corretivos e gesso agrícola. Scientia Agrícola, v.58, n.4, p.825-831, 2001.

GONÇALVES, J. R. P.; MOREIRA, A.; BULL, L. T.; CRUSCIOL, C. A. C.; BOAS, R. L. V.. Granulometria e doses de calcário em diferentes sistemas de manejo. Acta Scientiarum. Agronomy. Maringá, v.33, n.2, p.369-375, 2011.

A CBPC - Companhia Brasileira de Produção Científica (CNPJ: 11.221.422/0001-03) detém os direitos materiais desta publicação. Os direitos referem-se à publicação do trabalho em qualquer parte do mundo, incluindo os direitos às renovações, expansões e disseminações da contribuição, bem como outros direitos subsidiários. Todos os trabalhos publicados eletronicamente poderão posteriormente ser publicados em coletâneas impressas sob coordenação da Sustenere Publishing, da Companhia Brasileira de Produção Científica e seus parceiros autorizados. Os (as) autores (as) preservam os direitos autorais, mas não têm permissão para a publicação da contribuição em outro meio, impresso ou digital, em português ou em tradução. 